\title{
The Effects of Type 2 Diabetes and Postoperative Pneumonia on the Mortality in Inpatients with Surgery
}

\author{
Chun-ming Ma \\ Qin Liu \\ Ming-li Li \\ Mei-jing Ji \\ Jian-dong Zhang \\ Bo-hua Zhang \\ Fu-Zai Yin (D)
}

Department of Endocrinology, The First Hospital of Qinhuangdao, Qinhuangdao, Hebei 066000, People's Republic of China
This article was published in the following Dove Press journal: Diabetes, Metabolic Syndrome and Obesity: Targets and Therapy

Objective: The aim of the study was to explore the relationship between type 2 diabetes (T2DM) and postoperative pneumonia, and the effects of T2DM and postoperative pneumonia on the mortality in inpatients with surgery.

Methods: A retrospective study was conducted on 43,174 inpatients with surgery in The First Hospital of Qinhuangdao. These patients were divided into four groups according to T2DM and postoperative pneumonia, Group A subjects without T2DM and postoperative pneumonia, Group B subjects with T2DM only, Group C subjects with postoperative pneumonia only and Group D subjects with T2DM and postoperative pneumonia. Inhospital mortality was collected.

Results: The incidences of postoperative pneumonia were higher in patients with T2DM than patients without T2DM (T2DM 3.2\% vs Non-diabetes $1.7 \%, \chi^{2}=36.219, P<0.001$ ). The mortalities were $0.3 \%$ in Group A, $0.3 \%$ in Group B, $4.6 \%$ in Group C and $8.6 \%$ in Group D. In multiple logistic regression analysis, adjusted for sex, age, emergency admissions, coronary heart disease, heart failure, chronic kidney disease, hypoproteinemia, stroke and transient ischemic attack, the mortalities of Group C and Group D were 4.515 (95\% CI: $2.779 \sim 7.336, P<0.001)$ times and 8.468 (95\% CI: $3.567 \sim 20.099, P<0.001)$ times than the mortality of Group A.

Conclusion: T2DM is susceptible to postoperative pneumonia. The mortality increased in patients with postoperative pneumonia. When patients with T2DM and postoperative pneumonia at the same time, the mortality increased further. In T2DM patients with postoperative pneumonia, perioperative management should be improved for patient safety.

Keywords: type 2 diabetes, postoperative pneumonia, mortality

\section{Introduction}

In the last several decades, the prevalence of diabetes is increasing dramatically in China. The prevalence of type 2 diabetes mellitus (T2DM) was around $10 \%{ }^{1,2}$ As a result, the number of patients with T2DM undergoing surgical procedures has also increased. ${ }^{3}$ Diabetes was associated with surgical complications. Diabetes increased the perioperative major adverse cardiovascular and cerebrovascular events (MACCEs) and individual end points were also less favorable for patients with diabetes. ${ }^{4}$ In addition, diabetes increased the risks of postoperative acute renal failure, deep venous thrombosis, surgical site infection, urinary tract infection and hemorrhage. ${ }^{5-7}$ T2DM was an independent predictor for mortality after cardiac surgery and non-cardiac surgery., 8

Compared with non-diabetic populations, patients with T2DM are more likely to have postoperative pneumonia after surgery. Spanish Hospital Discharge Database
Correspondence: Fu-Zai Yin

Department of Endocrinology, The First Hospital of Qinhuangdao, Qinhuangdao Hebei 066000, People's Republic of China Tel +86-335-5908368

Fax +86-335-3032042

Email yinfuzai62@163.com 
shows that T2DM patients had a $21 \%$ higher incidence of postoperative pneumonia than nondiabetic patients in 2001-2015. ${ }^{10}$ The American College of Surgeons National Surgical Quality Improvement Program (ACS NSQIP) database also shows that T2DM was found to be an independent risk factor for postoperative pneumonia in orthopedic surgery. ${ }^{11,12}$ Postoperative pneumonia was a major cause of mortality after surgery. ${ }^{13}$ Several studies identify postoperative pneumonia as a predictor of short-term and long-term mortality after surgery. ${ }^{14-19}$ Is there a difference in the outcomes of postoperative pneumonia between patients with and without T2DM?

The aim of the study was to explore the relationship between T2DM and postoperative pneumonia, and the effects of T2DM and postoperative pneumonia on the mortality in inpatients with surgery.

\section{Methods}

\section{Subjects}

We performed a retrospective study. All subjects were inpatients with surgery from the First Hospital of Qinhuangdao between December 2014 and November 2018. The inclusion criteria included the following: 1) all patients were treated with an operation, 2) subjects were men and women over 18 years of age. The exclusion criteria included the following: 1) subjects with pneumonia before surgery, 2) subjects with type 1 diabetes, other specific types of diabetes, diabetes without clear type classification or pre-diabetes and 3) pregnancy. This study was approved by the ethics committee of the First Hospital of Qinhuangdao.

\section{Classification of Pneumonia and Diabetic Type}

Pneumonia was classified using the codes of International Classification of Diseases-10 (ICD-10) classifications for hospital admissions. For patients with pneumonia, the occurrence time of pneumonia was recorded. The previous pneumonia was defined as patients have pneumonia at the time of hospital admission or occurred pneumonia before surgery.

Diabetic types were classified using ICD-10. The codes of T2DM were included in the study. The codes of type 1 diabetes and other specific type diabetes were excluded. Nonspecific codes and codes of pre-diabetes were also excluded in the study.

These patients were divided into four groups according to T2DM and postoperative pneumonia, Group A subjects without T2DM and postoperative pneumonia, Group
B subjects with T2DM only, Group C subjects with postoperative pneumonia only and Group D subjects with T2DM and postoperative pneumonia.

\section{Data Collection}

All data were extracted from the Hospital Information System. Sociodemographic variables were collected and included: age, sex, hospital length of stay (LOS) and hospital cost. Clinical data were collected and included: chronic kidney disease (CKD), hypoproteinemia, heart failure, coronary heart disease (CHD), stroke \& transient ischemic attack (TIA). Emergency admissions were collected. Intensive care unit (ICU) admissions and inhospital mortality were also collected.

\section{Statistical Analyses}

All analyses were performed using the SPSS 11.5 statistical software (SPSS 11.5 for Windows; SPSS, Inc., Chicago, IL). Numerical variables were reported as mean \pm standard deviation. Comparisons were conducted between groups using the ANOVA. Categorical data were reported as abnormal subjects $(\%)$ and chi-square test was used. The incidence of postoperative pneumonia was compared between patients with T2DM and without T2DM. This comparison was stratified by sex and age. Multiple logistic regression models were used for modeling relationships between T2DM, postoperative pneumonia and mortality. $P<0.05$ was considered statistically significant.

\section{Results}

This study enrolled 43,174 inpatients with surgery $(21,255$ males and 21,919 females), age $51.5 \pm 16.3$ years. In these patients, 2917 patients $(6.8 \%)$ have T2DM. Seven hundred and sixty-four patients $(1.8 \%)$ had pneumonia after surgery. The incidences of postoperative pneumonia were higher in patients with T2DM than patients without T2DM (T2DM $3.2 \%$ vs Non-diabetes $\left.1.7 \%, \chi^{2}=36.219, P<0.001\right)$. The incidences of postoperative pneumonia between those with T2DM and those without T2DM were stratified by sex and age. The number of inpatients with surgery in each sex and age groups are shown in Supplementary Table 1. The incidences of postoperative pneumonia were higher in patients with T2DM for both sexes $(P<0.001)$. When patients were stratified by age group, patients with T2DM have higher incidences of postoperative pneumonia in $\sim 39$ years and $40 \sim 49$ years $(P<0.05)$ (Figure 1). Figure 2 shows the odds ratios (OR) and $95 \%$ confidence intervals $(\mathrm{CI})$ for postoperative pneumonia between surgical patients with and without T2DM 


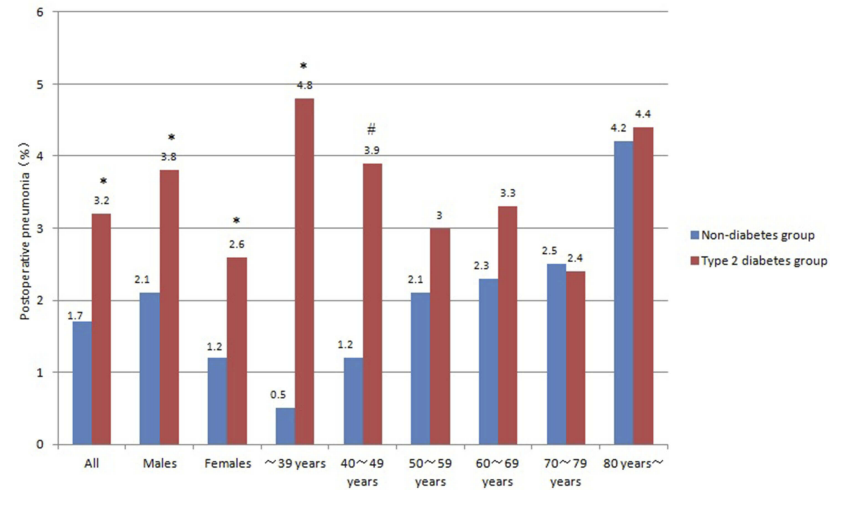

Figure I The postoperative pneumonia between surgical patients with and without type 2 diabetes. *Compare with non-diabetes group, $P<0.00 \mathrm{I} ;{ }^{*}$ compare with nondiabetes group, $P<0.01$.

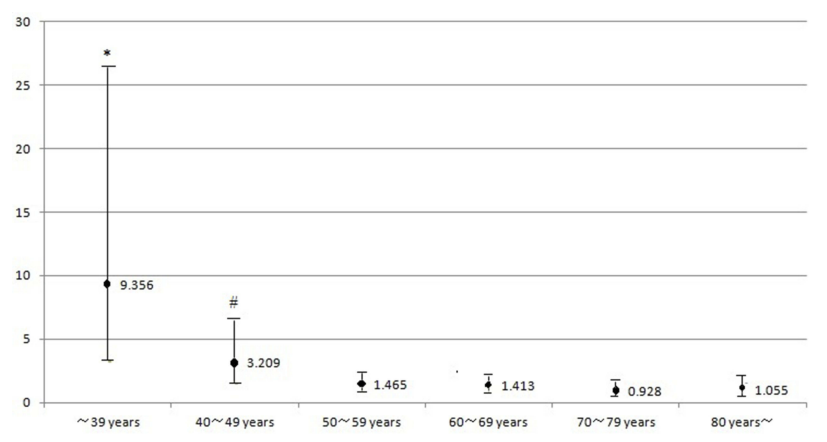

Figure 2 Odds ratios and $95 \%$ confidence intervals for postoperative pneumonia between surgical patients with and without type 2 diabetes stratified by age. Univariate logistic regression analysis, ${ }^{*} P<0.001,{ }^{*} P<0.01$.

stratified by age. In univariate logistic regression analysis, T2DM was associated with postoperative pneumonia in $~$ 39 years and $40 \sim 49$ year groups $(P<0.05)$. In multiple logistic regression analysis, adjusted for sex, age, emergency admissions, $\mathrm{CHD}$, heart failure, $\mathrm{CKD}$, hypoproteinemia, stroke and TIA, T2DM was an independent risk factor of postoperative pneumonia only in $\sim 39$ year groups $(\mathrm{OR}=3.621,95 \% \mathrm{CI}$ : $1.023 \sim 12.818, P=0.046)$ and $40 \sim 49$ year groups $(\mathrm{OR}=$ $2.167,95 \%$ CI: $1.008 \sim 4.659, P=0.048)$. Supplementary Figure 1 shows the type of surgery in inpatients with and without T2DM.

The characteristics of patients according to T2DM and postoperative pneumonia are shown in Table 1 . The frequencies of males were higher in Group $\mathrm{C}$ than Groups $\mathrm{A}$ and B $(P<0.05)$. Patients in Groups B, C and D were older than patients in Group A $(P<0.05)$. The frequencies of emergency admissions were lower in Group B than Group A $(P<0.05)$. The frequencies of emergency admissions were higher in Groups $\mathrm{C}$ and D than Group A $(P<0.05)$. The frequencies of CHD, heart failure, hypoproteinemia, stroke and TIA were higher in Groups B, C and D than Group A $(P<0.05)$. The frequencies of $\mathrm{CKD}$ were higher in Groups $\mathrm{B}$ and $\mathrm{D}$ than Group A $(P<0.05)$. The frequencies of heart failure, stroke and TIA were higher in Group D than Groups B and $\mathrm{C}(P<0.05)$. The frequencies of $\mathrm{CHD}$ and $\mathrm{CKD}$ were higher in Group D than Group $\mathrm{C}(P<0.05)$. The frequency of hypoproteinemia was higher in Group D than Group B $(P<0.05)$. The levels of hospital length of stay and hospital cost were significantly higher in Groups B, C and D than Group A $(P<0.05)$. The levels of hospital length of stay and hospital cost were significantly higher in Group D than Groups B and $\mathrm{C}(P<0.05)$ (Figure 3).

The frequencies of ICU admissions were $1.8 \%$ in Group A, 3.7\% in Group B, 18.8\% in Group C and $31.2 \%$ in Group D. In multiple logistic regression analysis, adjusted for sex, age, emergency admissions, CHD, heart failure, CKD, hypoproteinemia, stroke and TIA, the frequencies of ICU admissions of Groups B, C and D were 1.467 (95\% CI: $1.167 \sim 1.844, P=0.001)$ times, 3.885 (95\% CI: $3.039 \sim 4.968, P<0.001)$ times and $8.267(95 \%$ CI: $4.883 \sim 13.994, P<0.001)$ times than the ICU admissions of Group A (Table 2).

The mortalities were higher in patients with T2DM than patients without T2DM (T2DM $0.5 \%$ vs Non-diabetes $0.3 \%$, $\chi^{2}=4.107, P=0.043$ ). The mortalities were $0.3 \%$ in Group A, $0.3 \%$ in Group B, $4.6 \%$ in Group C and $8.6 \%$ in Group D. In multiple logistic regression analysis, adjusted for sex, age, emergency admissions, CHD, heart failure, CKD, hypoproteinemia, stroke and TIA, the mortalities of Group $\mathrm{C}$ and Group D were 4.515 (95\% CI: 2.779 7.336, $P<0.001)$ times and 8.468 (95\% CI: $3.567 \sim 20.099, P<0.001)$ times than the mortality of Group A (Table 3).

\section{Discussion}

Our study shows that surgical patients with T2DM had higher incidences of postoperative pneumonia. The differences in incidence were mainly observed in patients under 50-years-old. The mortalities were higher in patients occurred pneumonia after surgery, especially in patients with T2DM.

Consistent with previous results, ${ }^{10-12}$ patients with T2DM were more likely to have postoperative pneumonia after surgery. Unlike previous studies, the incidences of postoperative pneumonia were analyzed in different age groups in our study. In age-stratified analyses, the incidences of postoperative pneumonia increased with age group in patients without diabetes. However, the incidences of postoperative pneumonia have nothing to do 
Table I The Characteristics of Inpatients with Surgery in Four Groups

\begin{tabular}{|l|l|l|l|l|l|l|l|l|}
\hline Groups & $\begin{array}{l}\text { Sex } \\
\text { (Males/ } \\
\text { Females) }\end{array}$ & Age (Years) & $\begin{array}{l}\text { Emergency } \\
\text { Admissions } \\
{[n(\%)]}\end{array}$ & $\begin{array}{l}\text { CHD } \\
{[n(\%)]}\end{array}$ & $\begin{array}{l}\text { Heart } \\
\text { Failure } \\
{[n(\%)]}\end{array}$ & $\begin{array}{l}\text { Stroke } \\
\text { and TIA } \\
{[n(\%)]}\end{array}$ & $\begin{array}{l}\text { CKD [n } \\
(\%)]\end{array}$ & $\begin{array}{l}\text { Hypoproteinemia } \\
{[n(\%)]}\end{array}$ \\
\hline $\begin{array}{l}\text { Group } \\
\text { A (n=39,586) }\end{array}$ & $\begin{array}{l}19,397 / \\
20,189\end{array}$ & $50.5 \pm 16.3$ & $4845(12.2)$ & $1371(3.5)$ & $193(0.5)$ & $1062(2.7)$ & $119(0.3)$ & $345(0.9)$ \\
\hline $\begin{array}{l}\text { Group } \\
\text { B (n=2824) }\end{array}$ & $1384 / 1440$ & $63.2 \pm 11.3^{\mathrm{a}}$ & $141(5.0)^{\mathrm{a}}$ & $471(16.7)$ & $55(1.9)^{\mathrm{a}}$ & $363(12.9)^{\mathrm{a}}$ & $64(2.3)^{\mathrm{a}}$ & $63(2.2)^{\mathrm{a}}$ \\
\hline $\begin{array}{l}\text { Group } \\
\text { C (n=67I) }\end{array}$ & $420 / 251^{\mathrm{a}, \mathrm{b}}$ & $59.5 \pm 14.0^{\mathrm{a}, \mathrm{b}}$ & $270(40.2)^{\mathrm{a}, \mathrm{b}}$ & $59(8.8)^{\mathrm{a}, \mathrm{b}}$ & $38(5.7)^{\mathrm{a}, \mathrm{b}}$ & $\begin{array}{l}109(16.2)^{\mathrm{a},} \\
\mathrm{b}\end{array}$ & $4(0.6)^{\mathrm{b}}$ & $86(12.8)^{\mathrm{a}, \mathrm{b}}$ \\
\hline $\begin{array}{l}\text { Group } \\
\text { D (n=93) }\end{array}$ & $54 / 39$ & $62.0 \pm 13.5^{\mathrm{a}}$ & $27(29.0)^{\mathrm{a}, \mathrm{b}, \mathrm{c}}$ & $16(17.2)^{\mathrm{a}, \mathrm{c}}$ & $11(11.8)^{\mathrm{a}, \mathrm{b}, \mathrm{c}}$ & $\begin{array}{l}26(28.0)^{\mathrm{a}, \mathrm{b},} \\
\mathrm{c}\end{array}$ & $5(5.4)^{\mathrm{a}, \mathrm{c}}$ & $14(15.1)^{\mathrm{a}, \mathrm{b}}$ \\
\hline F or $\chi^{2}$ & 51.740 & 630.742 & 652.326 & 1151.548 & 500.909 & 1256.468 & 281.651 & 994.572 \\
\hline P & $<0.001$ & $<0.001$ & $<0.001$ & $<0.001$ & $<0.001$ & $<0.001$ & $<0.001$ & $<0.001$ \\
\hline
\end{tabular}

Notes: Group A: control group; Group B: type 2 diabetes group; Group C: postoperative pneumonia group; Group D: type 2 diabetes and postoperative pneumonia group. ${ }^{a}$ Compare with Group A, $P<0.05$; ${ }^{b}$ compare with Group B, $P<0.05$; ${ }^{c}$ compare with Group $C, P<0.05$. Numerical data are expressed as mean \pm SD.

Abbreviations: CHD, coronary heart disease; TIA, transient ischemic attack; CKD, chronic kidney disease; SD, standard deviation.

with the age group in patients with T2DM, fluctuated between $2.4 \%$ and $4.8 \%$. The ORs for postoperative pneumonia decreased with the increased age groups. These results indicated that the increased incidences appeared earlier in those with T2DM. The difference between the two groups begins to shrink after the age of 50 years.

The immune system protects against pathogen invasion. In diabetic patients, chronic dysmetabolism changed the immune response and accelerated immune aging. Adipocytokines are cytokines secreted by adipose tissue and correlated with T2DM. Adipocytokines, especially leptin, also play an important role in immune dysregulation. ${ }^{20}$ All this may contribute to the premature aging of the immune system in T2DM.

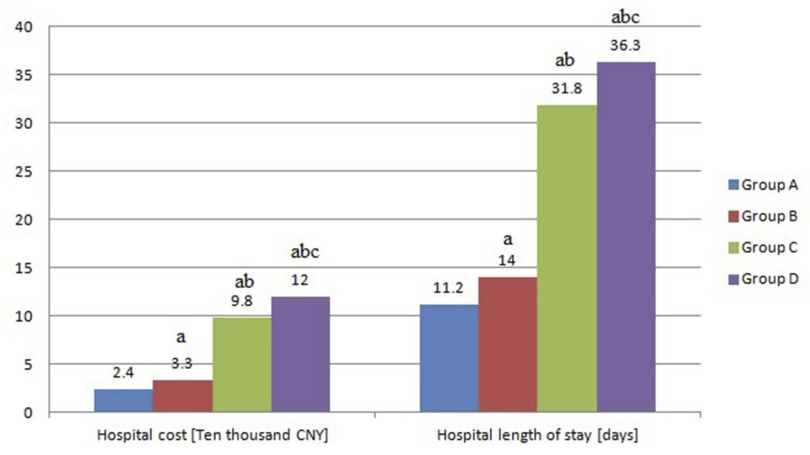

Figure 3 The hospital cost and length of stay of inpatients with surgery in four groups. Group A: control group; Group B: type 2 diabetes group; Group C: postoperative pneumonia group; GroupD: type 2 diabetes and postoperative pneumonia group. ${ }^{\text {a }}$ Compare with Group A, $P<0.05$; ${ }^{\text {c }}$ compare with Group B, $P<0.05$; 'compare with Group C, $P<0$.
Postoperative pneumonia is the third most common complication in surgical patients. Postoperative pneumonia increased ICU admissions, postoperative length of stay and hospital costs. ${ }^{21,22}$ Diabetes also increased the postoperative length of stay and hospital costs. ${ }^{23}$ In our study, hospital length of stay, hospital cost and ICU admissions were higher in patients with T2DM or postoperative pneumonia. Hospital length of stay, hospital cost and ICU admissions further increased in patients with T2DM occurred postoperative pneumonia.

The incidences of postoperative pneumonia differed between the various surgeries. In ACS NSQIP, the incidence of postoperative pneumonia for all surgeries was $1.3 \%{ }^{24}$ The incidence of postoperative pneumonia was $1.8 \%$ in our study. Whether in those with T2DM or in those without T2DM, postoperative pneumonia all increased the mortality in surgical patients and the mortality further increased in patients with T2DM. When postoperative pneumonia occurred in patients with $\mathrm{T} 2 \mathrm{DM}$, this often means worse prognosis in these patients.

These results may be due to the following mechanisms. First, T2DM can destroy innate immunity in pulmonary, and more susceptible to infections. In an animal model, the expression of macrophage inflammatory protein 2 , an important mediator of lung neutrophil recruitment, was impaired of in the alveolar macrophages. ${ }^{25}$ Toll-like receptors (TLRs) are important for the host response in lung infection. Monocytes from patients with diabetes were suppressed expression of TLR2 and TLR4. The expression of 
Table 2 The Relationship Between Type 2 Diabetes, Postoperative Pneumonia and ICU Admissions in Inpatients with Surgery

\begin{tabular}{|c|c|c|c|c|c|}
\hline \multirow[t]{2}{*}{ Groups } & \multirow[t]{2}{*}{$n(\%)$} & \multicolumn{2}{|l|}{ Model I } & \multicolumn{2}{|l|}{ Model 2} \\
\hline & & OR(95\% Cl) & $P$ & OR(95\% Cl) & $P$ \\
\hline Group A $(n=39,586)$ & $7 \mid 4(1.8)$ & I & & I & \\
\hline Group B $(n=2824)$ & $105(3.7)$ & $2.102(1.707 \sim 2.590)$ & $<0.001$ & $1.467(1.167 \sim 1.844)$ & 0.001 \\
\hline Group C $(n=67 I)$ & $126(\mid 8.8)$ & $12.587(10.229 \sim 15.488)$ & $<0.001$ & $3.885(3.039 \sim 4.968)$ & $<0.001$ \\
\hline Group D $(n=93)$ & $29(31.2)$ & $24.669(15.810 \sim 38.494)$ & $<0.001$ & $8.267(4.883 \sim 13.994)$ & $<0.001$ \\
\hline
\end{tabular}

Notes: Group A: control group; Group B: type 2 diabetes group; Group C: postoperative pneumonia group; GroupD: type 2 diabetes group and postoperative pneumonia group. Model I: univariate logistic regression analysis. Model 2: multiple logistic regression analysis, adjusted for sex, age, emergency admissions, CHD, heart failure, CKD, hypoproteinemia, stroke and TIA.

Abbreviations: ICU, intensive care unit; $\mathrm{OR}$, odds ratio; $\mathrm{Cl}$, confidence interval; $\mathrm{CHD}$, coronary heart disease; CKD, chronic kidney disease; TIA, transient ischemic attack.

Table 3 The Relationship Between Type 2 Diabetes, Postoperative Pneumonia and Mortality in Inpatients with Surgery

\begin{tabular}{|c|c|c|c|c|c|}
\hline \multirow[t]{2}{*}{ Groups } & \multirow[t]{2}{*}{$n(\%)$} & \multicolumn{2}{|l|}{ Model I } & \multicolumn{2}{|l|}{ Model 2} \\
\hline & & OR(95\% Cl) & $P$ & OR(95\% Cl) & $\mathbf{P}$ \\
\hline Group A $(n=39,586)$ & $99(0.3)$ & I & & I & \\
\hline Group B $(n=2824)$ & $8(0.3)$ & $\mathrm{I} .133(0.55 \mathrm{I} \sim 2.33 \mathrm{I})$ & 0.734 & $0.694(0.318 \sim 1.516)$ & 0.359 \\
\hline Group C $(n=671)$ & $3 I(4.6)$ & $19.320(12.810 \sim 29.137)$ & $<0.001$ & $4.515(2.779 \sim 7.336)$ & $<0.001$ \\
\hline Group D (n=93) & $8(8.6)$ & $37.540(|7.7| 2 \sim 79.565)$ & $<0.001$ & $8.468(3.567 \sim 20.099)$ & $<0.001$ \\
\hline
\end{tabular}

Notes: Group A: control group; Group B: type 2 diabetes group; Group C: postoperative pneumonia group; GroupD: type 2 diabetes and postoperative pneumonia group. Model I: univariate logistic regression analysis. Model 2: multiple logistic regression analysis, adjusted for sex, age, CHD, heart failure, CKD, hypoproteinemia, stroke and TIA.

Abbreviations: ICU, intensive care unit; $\mathrm{OR}$, odds ratio; $\mathrm{Cl}$, confidence interval; $\mathrm{CHD}$, coronary heart disease; CKD, chronic kidney disease; TIA, transient ischemic attack.

TLR2 and TLR4 further declines in diabetes patients with pneumonia. $^{26,27}$ Monocytes and macrophages can directly phagocytose pathogens. The phagocytic and killing capability of alveolar macrophages from diabetic mice decreased. ${ }^{28}$ In adaptive immunity, T2DM have a diminished pathogenspecific memory CD4+ and Th17 response, and low percentages of $\mathrm{CD}+\mathrm{T}$-cells in response to $S$. pneumoniae stimulation. $^{29}$ Second, hyperglycaemia also increased airway surface liquid glucose concentrations which drive the proliferation of bacteria. ${ }^{30}$ Third, T2DM is associated with impaired pulmonary function and reduced cardiorespiratory fitness. $^{31,32}$

There are limitations to our study. First, severity assessment scores of pneumonia, such as Pneumonia Severity Index, were not evaluated in our study. Second, the number of type 2 diabetes patients was small in $\sim 39$ year groups. This maybe causes a high OR in $\sim 39$ year groups. And this result should be proved by a larger sample size in $\sim 39$ year groups. Third, other confounding factors, such as smoking status, alcohol use, body mass index, diabetes complications, cancers, and lung disease, were not evaluated in our study.

In summary, T2DM is susceptible to postoperative pneumonia. The mortality increased in patients with postoperative pneumonia. In patients with T2DM and postoperative pneumonia at the same time, the mortality increased further. In
T2DM patients with postoperative pneumonia, perioperative management should be improved for patient safety.

\section{Statement}

The experiment was approved by the ethics committee of the First Hospital of Qinhuangdao (Protocol number: 2019D006). The study is a retrospective study. Data were extracted from the Hospital Information System. Personal information of patients, such as name, telephone number, address, was not extracted. Informed consent was waived by the ethics committee of the First Hospital of Qinhuangdao and compliance with the Declaration of Helsinki.

\section{Acknowledgment}

Chun-ming Ma and Qin Liu are joint first authors.

\section{Disclosure}

The authors report no conflicts of interest in this work.

\section{References}

1. Yang W, Lu J, Weng J, et al. Prevalence of diabetes among men and women in China. $N$ Engl J Med. 2010;362(12):1090-1101. doi:10.1056/NEJMoa0908292

2. $\mathrm{Xu} \mathrm{Y}$, Wang $\mathrm{L}, \mathrm{He} \mathrm{J}$, et al. Prevalence and control of diabetes in Chinese adults. JAMA. 2013;310(9):948-959. doi:10.1001/jama.2013.168118 
3. Chuah LL, Papamargaritis D, Pillai D, Krishnamoorthy A, le Roux CW. Morbidity and mortality of diabetes with surgery. Nutr Hosp. 2013;28(Suppl 2):47-52. doi:10.3305/nh.2013.28.sup2.6713

4. Newman JD, Wilcox T, Smilowitz NR, Berger JS. Influence of diabetes on trends in perioperative cardiovascular events. Diabetes Care. 2018;41(6):1268-1274. doi:10.2337/dc17-2046

5. Mahure S, Mollon B, Quien M, Karia R, Zuckerman JD, Kwon YW. Impact of diabetes on perioperative complications in patients undergoing elective total shoulder arthroplasty. Bull Hosp Jt Dis (2013). 2017;75(3):173-179.

6. Luo W, Sun R-X, Jiang H, Ma XL. The effect of diabetes on perioperative complications following spinal surgery: a meta-analysis. Ther Clin Risk Manag. 2018;14:2415-2423. doi:10.2147/TCRM

7. Marchant MH Jr., Viens NA, Cook C, Bolognesi MP. The impact of glycemic control and diabetes mellitus on perioperative outcomes after total joint arthroplasty. J Bone Joint Surg Am. 2009;91 (7):1621-1629. doi:10.2106/JBJS.H.00116

8. Kogan A, Ram E, Levin S, et al. Impact of type 2 diabetes mellitus on short- and long-term mortality after coronary artery bypass surgery. Cardiovasc Diabetol. 2018;17(1):151. doi:10.1186/s12933-018-0796-7

9. Punthakee Z, Iglesias PP, Alonso-Coello P, et al. Association of preoperative glucose concentration with myocardial injury and death after non-cardiac surgery (GlucoVISION): a prospective cohort study. Lancet Diabetes Endocrinol. 2018;6(10):790-797. doi:10.1016/S2213-8587(18) 30205-5

10. Lopez-de-Andres A, Perez-Farinos N, de Miguel-díez J, et al. Type 2 diabetes and postoperative pneumonia: an observational, populationbased study using the Spanish Hospital Discharge Database, 2001-2015. PLoS One. 2019;14(2):e0211230. doi:10.1371/journal. pone. 0211230

11. Patterson DC, Shin JI, Andelman SM, Olujimi V, Parsons BO. Increased risk of 30-day postoperative complications for diabetic patients following open reduction-internal fixation of proximal humerus fractures: an analysis of 1391 patients from the American College of Surgeons National Surgical Quality Improvement Program database. JSES Open Access. 2017;1(1):19-24. doi:10.1016/j.jses.2017.03.006

12. Bohl DD, Mayo BC, Massel DH, et al. Incidence and risk factors for pneumonia after posterior lumbar fusion procedures: an ACS-NSQIP study. Spine (Phila Pa 1976). 2016;41(12):1058-1063. doi:10.1097/ BRS.0000000000001389

13. Martin LF, Asher EF, Casey JM, Fry DE. Postoperative pneumonia. Determinants of mortality. Arch Surg. 1984;119(4):379-383. doi:10.1001/archsurg.1984.01390160015003

14. Kjorholt KE, Kristensen NR, Prieto-Alhambra D, Johnsen SP, Pedersen AB. Increased risk of mortality after postoperative infection in hip fracture patients. Bone. 2019;127:563-570. doi:10.1016/j. bone.2019.07.023

15. Bullock TK, Waltrip TJ, Price SA, Galandiuk S. A retrospective study of nosocomial pneumonia in postoperative patients shows a higher mortality rate in patients receiving nasogastric tube feeding. Am Surg. 2004;70(9):822-826.

16. Tamagawa A, Aoyama T, Tamagawa $\mathrm{H}$, et al. Influence of postoperative pneumonia on esophageal cancer survival and recurrence. Anticancer Res. 2019;39(5):2671-2678. doi:10.21873/anticanres.13392

17. Takeuchi M, Kawakubo H, Mayanagi S, et al. Postoperative pneumonia is associated with long-term oncologic outcomes of definitive chemoradiotherapy followed by salvage esophagectomy for esophageal cancer. J Gastrointest Surg. 2018;22(11):1881-1889. doi:10.1007/s11605-018$3857-\mathrm{z}$
18. Tanaka S, Geneve C, Tebano G, et al. Morbidity and mortality related to pneumonia and TRACHEOBRONCHITIS in ICU after lung transplantation. BMC Pulm Med. 2018;18(1):43. doi:10.1186/s12890018-0605-9

19. Jamali S, Dagher M, Bilani N, et al. The effect of preoperative pneumonia on postsurgical mortality and morbidity: a NSQIP analysis. World J Surg. 2018;42(9):2763-2772. doi:10.1007/s00268018-4539-4

20. Moura J, Madureira P, Leal EC, Fonseca AC, Carvalho E. Immune aging in diabetes and its implications in wound healing. Clin Immunol. 2019;200:43-54. doi:10.1016/j.clim.2019.02.002

21. Sabate S, Mazo V, Canet J. Predicting postoperative pulmonary complications: implications for outcomes and costs. Curr Opin Anaesthesiol. 2014;27(2):201-209. doi:10.1097/ACO.0000000 000000045

22. Le CD, Lehman E, Aziz F. Development of postoperative pneumonia after endovascular aortic aneurysm repair is associated with an increased length of intensive care unit stay. Cureus. 2019;11(4): e4514.

23. Malone M, Lau NS, White J, et al. The effect of diabetes mellitus on costs and length of stay in patients with peripheral arterial disease undergoing vascular surgery. Eur J Vasc Endovasc Surg. 2014;48 (4):447-451. doi:10.1016/j.ejvs.2014.07.001

24. Chughtai M, Gwam CU, Khlopas A, et al. The incidence of postoperative pneumonia in various surgical subspecialties: a dual database analysis. Surg Technol Int. 2017;30:45-51.

25. Amano H, Yamamoto H, Senba M, et al. Impairment of endotoxininduced macrophage inflammatory protein 2 gene expression in alveolar macrophages in streptozotocin-induced diabetes in mice. Infect Immun. 2000;68(5):2925-2929. doi:10.1128/IAI.68.5.29252929.2000

26. Que Y, Shen X. Changes in blood monocyte Toll-like receptor and serum surfactant protein A reveal a pathophysiological mechanism for community-acquired pneumonia in patients with type 2 diabetes. Intern Med J. 2016;46(2):213-219. doi:10.1111/ imj. 12978

27. Khondkaryan L, Margaryan S, Poghosyan D, Manukyan G. Impaired inflammatory response to LPS in type 2 diabetes mellitus. Int J Inflam. 2018;2018:2157434. doi:10.1155/2018/2157434

28. Alim MA, Sikder S, Bridson TL, Rush CM, Govan BL. Antimycobacterial function of macrophages is impaired in a diet induced model of type 2 diabetes. Tuberculosis (Edinb). 2017;102:47-54. doi:10.1016/j.tube.2016.12.002

29. Martinez PJ, Mathews C, Actor JK, et al. Impaired CD4+ and T-helper 17 cell memory response to Streptococcus pneumoniae is associated with elevated glucose and percent glycated hemoglobin A1c in Mexican Americans with type 2 diabetes mellitus. Transl Res. 2014;163(1):53-63. doi:10.1016/j.trsl.2013.07.005

30. Baker EH, Baines DL. Airway glucose homeostasis: a new target in the prevention and treatment of pulmonary infection. Chest. 2018;153 (2):507-514. doi:10.1016/j.chest.2017.05.031

31. Huang H, Guo Q, Li L, et al. Effect of type 2 diabetes mellitus on pulmonary function. Exp Clin Endocrinol Diabetes. 2014;122 (6):322-326. doi:10.1055/s-00000017

32. Wilms B, Ernst B, Thurnheer M, Spengler CM, Schultes B. Type 2 diabetes is associated with lower cardiorespiratory fitness independent of pulmonary function in severe obesity. Exp Clin Endocrinol Diabetes. 2017;125(5):301-306. doi:10.1055/s-0043-100102 


\section{Publish your work in this journal}

Diabetes, Metabolic Syndrome and Obesity: Targets and Therapy is an international, peer-reviewed open-access journal committed to the rapid publication of the latest laboratory and clinical findings in the fields of diabetes, metabolic syndrome and obesity research. Original research, review, case reports, hypothesis formation, expert opinion and commentaries are all considered for publication. The manuscript management system is completely online and includes a very quick and fair peer-review system, which is all easy to use. Visit http://www.dovepress.com/testimonials.php to read real quotes from published authors.

Submit your manuscript here: https://www.dovepress.com/diabetes-metabolic-syndrome-and-obesity-targets-and-therapy-journal 